\title{
PHYSICS DOES IT BETTER: SO WHY BE AFRAID OF PHILOSOPHY?
}

\author{
Livio De Fabrizio \\ Department of Mathematics and Physics, Università degli Studi Roma Tre \\ I-00146 Rome, Italy
}

11 June 2020

\begin{abstract}
Physics is the best tool to investigate nature ("physics does it better") and philosophy, far from being a competitor, is a companion in its quest for knowledge ("so why be afraid of philosophy?"). In this article it is observed that the anti-philosophical positions within the modern scientific community come from misconceptions and that scientists can't be "against philosophy". As a conclusion, the expressions "laws of physics" and "laws of nature" are discussed.
\end{abstract}

\section{Contents}

1 Introduction 2

2 Philosophy and science $\quad 2$

3 Who's afraid of philosophy? 5

4 The "laws of nature" $\quad 7$

$\begin{array}{ll}\text { Bibliography } & 10\end{array}$ 


\section{Introduction}

In a recent article [1], Stenger et al. move some objections against a today's widespread opinion, defended by such scientists as Hawking, Krauss, and Weinberg, of "uselessness" of philosophy, science being seen as its contemporary "evolution" or replacement; the authors assert that it is impossible to avoid philosophy also in physical research and conclude that, possibly, only metaphysics is to be viewed with suspicion nowadays. Similarly, papers by Rovelli (et al.), also inspired by the opinion defended by the aforementioned scientists, concern the importance of philosophy in itself and, in particular, in the context of physics and modern science: in [2] the critique takes inspiration from Aristotle's Protrepticus [3] and, at the end, also the importance of physics and science in philosophy is shortly pointed out; in [4] the role is emphasized of the philosophical inquiry in scientific research and a greater cooperation between the two fields is encouraged. The reading of these publications prompts me to add some equally simple but more fundamental considerations; by doing this, my attempt is to highlight evidence, just as by uprooting a plant one tries to get evidence of its roots, so I'm not going into any deep (philosophical!) analysis which, being subject to a philosophical language, couldn't be addressed to those by whom philosophy is actually rejected. Rather, I'm showing in the next sections that the rejection of philosophy, anything but universal in the scientific community, just emerges where lack of awareness or misconception exist about what philosophy is.

\section{Philosophy and science}

My father used to say (probably quoting Cicero or someone else) that, before speaking, it is necessary to reach a common agreement on the meaning of words. So, what is the meaning of the word philosophy?

In his book Dreams of a Final Theory. The Scientist's Search for the Ultimate Laws of Nature [5], Weinberg gives to the seventh chapter the sinister title "Against Philosophy", discussing about the "unreasonable ineffectiveness" (page 169) of this discipline. For example, at the beginning, he states that although out of philosophy "after all our science evolved", "the insights of philosophers have occasionally benefited physicists, but generally in a negative fashion - by protecting them from the preconceptions of other philosophers" (page 166). In several pages, Weinberg gives a number of examples which, although deserving a more specific analysis, may be here summed up by using his own words: he is writing 'against preconceptions', against prejudices. There is no question that, in human history, a series of ideas have been taken for dogmas and many philosophical or political thoughts have been exploited or carried to extremes. Anyway, Plato is not Platonism, Aristotle is not Aristotelism, science is not scientism, alcohol is not alcoholism, a culture is not the dullness, abuses or preconceptions which, unfortunately, it helps to create. While founding modern science, Galileo didn't dispute Aristotle, but rigid, ideological Aristotelism. In this respect, I want to recall what is highlighted in [6]: "in a letter a month later, he [Galileo] emphasizes the fact that Aristotle put experience before reasoning and concludes ' $\mathrm{I}$ am sure that if Aristotle would return to Earth 
he would accept me among his followers on account of my few but conclusive contradictions to him" ". So, philosophy is not ideology and preconceptions.

At the beginning of [7], Hawking and Mlodinow write: "How can we understand the world in which we find ourselves? How does the universe behave? What is the nature of reality? Where did all this come from? Did the universe need a creator? Most of us do not spend most of our time worrying about these questions, but almost all of us worry about them some of the time. Traditionally these are questions for philosophy, but philosophy is dead. Philosophy has not kept up with modern developments in science, particularly physics. Scientists have become the bearers of the torch of discovery in our quest for knowledge". Also in this case, a definition of philosophy is not given but, as a matter of fact, it is treated as a discipline oriented to a "quest for knowledge"; moreover, although it has been specified that those are "questions for philosophy", it remains unspecified if it is needed for philosophy to look up the answers. One can say that the scientist has a problem and seeks the solution, the philosopher has a solution and seeks the problem: this sentence may be interpreted as funny and philosophobic (and, obviously, very simplistic) but also, beyond appearances, as a very serious one. Hawking implicitly considers philosophy as a kind of alchemy or astrology, namely disciplines which more or less served their purpose but now have been definitely surpassed by something much better: science. Unfortunately, philosophy is not alchemy, astrology, pseudoscience, or some bad science; philosophy is not Tychonic astronomy or aether theory, nor it is looking for some magical stone (the philosopher's stone, exactly). Among the questions proposed by Hawking, once addressed to philosophy and now supposed to concern physics, we can also insert "what is physics?": likely, this question (and, possibly, the corresponding answer) is not an object of study of physics (rather, of philosophy, or of philosophy of physics if you prefer). In [1] and [2] also astrophysicist and science communicator deGrasse Tyson is mentioned, whose opinion on the subject doesn't appear in fact to be clear: during a debate [8] with Richard Dawkins he says that "the philosopher is the would-be scientist but without a laboratory", soon after admitting that there are of course other fields in philosophy such as political or ethical philosophy and, finally, agreeing with Dawkins who observes that there's also philosophy of science doing many pretty things, but that, after all, it's made by "scientists who are also trained in philosophy". The idea of philosophy arising in this case is a bit confusing, but it seems that at least some parts of philosophy have to do with science, and these parts are a form of deductive (not experimental) science, however a surrogate of science or a failed science. As if philosophers were pre-Galileans who still think that we can study the physical world without math and experiments. Really, it is no coincidence that philosophy has a different name: it is a different thing with different purposes. No doubt, it cannot be such a contradictory thing as a deviant science including a subfield, concerning standard science, which is made by standard scientists. Instead, Lawrence Krauss disparages philosophy of science, too: "the worst part of philosophy is the philosophy of science; the only people, as far as I can tell, that read work by philosophers of science are other philosophers of science" [9], then observing that "science progresses and philosophy doesn't", apparently presuming this statement to show a disadvantage of philosophy, which would aim to some kind of progress. In lack of a definition 
of progress, we may think Krauss unconsciounsly refers to scientific progress. But, again, starting from the word philosophy we are led back to science. So, philosophy is not science.

Sometimes, also Feynman is called into question as a detractor of philosophy: actually, although of quite a pragmatist, its position is a bit more interesting. Feynman did not disdain to use philosophy, rather he affirmed "it isn't the philosophy that gets me, it's the pomposity. If they'd just laugh at themselves! (...) If they'd explain that this is their best guess... But so few of them do" [10].

In conclusion, many objections appear to say, in a few words, "philosophy is not good physics", or "philosophy is not good science", or "philosophers don't do good science": yes, of course, all these people, they're right. They are, for the most part, great scientists who know very well their job: they know, better than anyone, that philosophy isn't and can't be good science. In fact, as just confirmed, philosophy is not science, and philosophers don't aim to become scientists: they generally care about science and scientists just no more than scientists care about philosophy and philosophers. Physicists do it better: so, why be afraid of philosophers? Philosophers of science, obviously, must care about science. "Philosophy of science is about as useful to scientists as ornithology is to birds" (a quotation often, but probably wrongly, attributed to Feynman) is many times simply true, as much as it is true, anyway, that ornithology is useful to us. In other words, the key observation is that ornithologists cannot continue to do the perfect ornithologists without birds, whereas birds can continue to do the perfect birds without ornithology; but, evidently, they are birds and birds will remain. What about anthropology?

So far, the deconstructing part: what is not philosophy. And it could be enough. But I also want to try to be constructive, which obviously is by far a more difficult task: so, again, what is philosophy? Surely, this is a very philosophical question, but, once again, why be afraid: since it is philosophical as, more or less, any question. Arguably, less philosophical than why live or why do science. More on that subject: what is love of wisdom? What is love? What is wisdom? What is knowledge? What is science? What is physics? What is what? What is "what is what?"? What? Definitions of philosophy are everywhere: the Oxford English Dictionary [11] says "the study of the fundamental nature of knowledge, reality, and existence, especially when considered as an academic discipline", or, by extension, "a theory or attitude that acts as a guiding principle for behaviour"; Merriam-Webster [12], on its part, "all learning exclusive of technical precepts and practical arts", "a discipline comprising as its core logic, aesthetics, ethics, metaphysics, and epistemology" or "pursuit of wisdom". Wikipedia [13] defines philosophy as "the study of general and fundamental questions about existence, knowledge, values, reason, mind, and language", whereas according to Encyclopedia Americana [14] "no satisfactory answer to the question, What is philosophy? can be derived either from the meaning of the word, or from the consensus of opinion expressed by writers on philosophy, unless these opinions are themselves subjected to comparison and criticism from the philosophic point of view" and according to Encyclopedia of Philosophy [15] "defining philosophy is itself a philosophical problem". So, what are we rejecting, or what are we defending? I'd say, our idea of philosophy. For some, a deep and complex idea, for others, 
a simple one, and still others have no idea: to each his own philosophy! I think that any definition must imply that doing philosophy is thinking, reasoning; in the most general and pure way. Hence, in particular, there are no principles to invalidate, because it is not like a religion, based on its prophets, commandments, holy books, nor like a science, based on experimental laws and postulates.

Physics, for its part, generally enjoys simpler definitions, such as the science that studies "nature", or "matter, motion, space, time and energy" (okay, not so simpler). What is matter? Yes, you know, particles... okay, particles are excitations of fields. So, what are fields? Are they a manifestation of Spinoza's substance? No doubt, physics is knowledge; moreover, it can provide explanations about human mechanisms underlying knowledge. Nevertheless, it would be hard to say that it is really about knowledge. At least, it would be very philosophical to say it.

\section{Who's afraid of philosophy?}

It's something strange to not see philosophy in all we think, say, and do. We can make this discussion terribly obvious: as Aristotle said, and as Rovelli recalls in his paper [2], "whoever thinks it necessary to philosophize must philosophize, and those who think we should not philosophize must philosophize to show that we must not philosophize; therefore one must philosophize in any case or leave here, bidding farewell to life, since all other things seem to be just talk and nonsense" (from Protrepticus, B6, see also [3]). To each his own philosophy. Stenger, Lindsay, and Boghossian also observe that "all of the prominent critics of philosophy whose views we have discussed think very deeply about the source of human knowledge. That is, they are all epistemologists. The best they can say is they know more about science than (most) professional philosophers and rely on observation and experiment rather than pure thought - not that they aren't philosophizing. Certainly, then, philosophy is not dead. That designation is more aptly applied to pure-thought variants like those that comprise cosmological metaphysics" [1]. Moreover, to not see philosophy is very sad and, above all, dangerous. Modern society is going to imprison itself in a mere science-technology binomial pair, a kind of self-powered device Heidegger, though not a scientist, just because not a scientist, clearly saw many decades ago (see for example [16]): so, science really progresses? In what sense? If we don't reflect on these concerns, we are ignoring not only philosophy and the fact that we are positivists, but also a good deal of quality science fiction. Of course, Heidegger had its own philosophy, romantic and metaphysical; of course, there were philosophers, in the past (particularly before modern science), who pursued great designs, rigid systems in which they tried to fit everything: just like many scientists do, still today. There are philosophers talking about human race and nature and having no idea of modern science, philosophers of politics putting ideology before reasoning; and there are scientists doing bad philosophy, as much bad as would be the science done by the best of the philosophers.

Inspired by Aristotle's statement about the unavoidability of philosophy, Rovelli rightly observes that "in declaring the uselessness of philosophy, Weinberg, Hawking, and other 'anti- 
philosophical' scientists are in fact paying homage to the philosophers of science they have read, or whose ideas they have absorbed from their environment" [2], leading their positions back to neo-positivism and the Vienna circle, as well as to Popper and Kuhn. Stenger, Lindsay, and Boghossian rather go back to platonism (which they carefully write with lowercase 'p' in order to make a distinction with Plato), then observing that "those who hold to a platonic view of reality are being disingenuous when they disparage philosophy. They are adopting the doctrine of one of the most influential philosophers of all time. That makes them philosophers, too" [1]. Of course, they, first of all, could belong to a philosophical current called scientism, except their arguments are a little vague to be considered as philosophical in a strong sense. Sure, they are influenced by positivism (a 19th century philosophy, preceding Einstein's relativity and quantum theory) and neo-positivism, or physicalism, but after all action and reaction are almost the same thing: Wittgenstein states in its Tractatus Logico-Philosophicus [17] (one of the centers the Vienna Circle revolved around) that "the limits of my language mean the limits of my world" (proposition 5.6), which, from one hand, sounds like "stop doing all that philosophy!" and, from the other, says "wait, all you know is language" and all your problems are grammar. Aristotle's "talk and nonsense" are, we can say, just very bad grammar. Wittgenstein tried to regard philosophical problems as grammatical problems; be that as it may, he was a deep thinker, so much that he came to a very modern definition of philosophy: it is an activity (i'd say again, thinking and reasoning!). Actually, Wittgenstein's philosophy of language also recalls Nietzsche when talking about "movable hosts of metaphors" [18]. What's more, Nietzsche actually understood that future philosophers would be specialists and experimenters: in a sense, scientists, but still, philosophers! As a matter of fact, philosophy has had its progress: it looked forward very well. No surprise, after all, since philosophy is not a discipline, rather an activity! The fact is, philosophy doesn't invent anything. Societies produce ways of being and thinking that, once observed, elucidated and rewritten in more beautiful prose, become philosophy, which influences science: in the past, it generated science, because Galileo, and Newton too, however revolutionary men, thought according to the canons of Plato and Aristotle, by far the most influential philosophers of their time. Science produces technology which, in turn, modifies and produces science which, no doubt, influences and modifies philosophy which is given back to society which again, in turn, with its resettlement, helps new philosophy to emerge, and no end is easy to predict. Who thinks that philosophy is of no use in science or of no use at all missed not only the history lesson, or today's evidence (in fields such as neuroscience, philosophy is at the forefront), or, even, the logical, obvious Aristotle's aforementioned lesson, but, above all, Socrates' paradoxical lesson, from "I know that I know nothing" to its maieutics. Just not everyone knows that also Greek philosophy nearly got burnt, until Socrates, more than anyone else, understood that philosophy had to be intensive rather than extensive.

But I don't want to run the risk of speaking about philosophy. The problem is that philosophy and science, which is a part of natural philosophy, moved guiltily away from each other: many philosophers think they can philosophize as if physics and, in general, science, didn't exist, and many physicists discovered they can do physics, from a technical point of view, 
without (high) philosophy (remember the birds), also believing (wrongly) they can do that without philosophy at all (remember Aristotle). The aforementioned detractors of philosophy just appear to think of philosophy as the study of nature by pure reasoning and without doing experiments: so, also mathematics has to be rejected. Could we? We can be fairly useful technicians of philosophy (who refuse to talk about physics), very useful technicians of physics (refusing to talk about philosophy) or, best of all, men and women of culture, who not only do, but reflect on what they do. Physics is the best tool to study the physical world, and how could it be otherwise? Philosophy, far from being a competitor, is a companion. So, who's afraid of philosophy? Who's afraid of thinking and of questioning his own certitudes and assumptions? And yes, philosophy could be done by scientists, but they ought to be very nontechnical and open-minded thinkers; even, science could be done by philosophers, provided they be also well aware of science and its methods, and adequately trained in mathematics. There is not philosophy, or physics, and so on, after all. There is culture.

\section{The "laws of nature"}

Motivated by the subtitle of [5], I want to conclude only observing that what has been said, having to do with the interpretation of science and its achievements, also applies to the frequent use of the expression "laws of nature" (or, "of Nature"). There are laws in Codes, in religions, non-written laws in families. There are laws in mathematics, at times believed to be perfect and absolute; even, Leibniz pursued the idea of a mathematical, logical language (the characteristica universalis) which could resolve all disputes, his interest being, after all, practical, because he was also a diplomat. Physics is made by propositions that, at a given time, must be taken to be "true" (that's to say, must be used by scientists as tools for their work) and may be principles and postulates, mathematical propositions such as theorems, experimental evidences. Which, however, are nothing but statistical results, and if you go deeper, you'll probably get better statistics, as the history of physics teaches us, from Aristotelian physics [6] to classical physics and to quantum physics. It is worth to say that these things were quite well expressed in Nietzsche's critique of truth (also scientific truth), before the rise of quantum theory and modern relativity: what we consider to be a truth, or a law, is an abstraction of convenience made at a given level of resolution. What if we go deeper, to a better resolution? All this despite some scientists who, in the same period, considered physics as an almost "dead subject", and despite Michelson's statement: "while it is never safe to affirm that the future of Physical Science has no marvels in store even more astonishing than those of the past, it seems probable that most of the grand underlying principles have been firmly established and that further advances are to be sought chiefly in the rigorous application of these principles to all the phenomena which come under our notice. It is here that the science of measurement shows its importance - where quantitative work is more to be desired than qualitative work. An eminent physicist remarked that the future truths of physical science are to be looked for in the sixth place of decimals" [19]. In other words, as we know, physical theories have not to be demonstrated, rather they may be falsified. Anyway, the use of the 
expression "laws of physics" seems to be, from a linguistic point of view, justified; "all that conformity to law, which impresses us so much in the movement of the stars and in chemical processes, coincides at bottom with those properties which we bring to things. Thus it is we who impress ourselves in this way" [18]. But, when using the expression "laws of nature" at least three questions arise: first, what is nature (or Nature), then, whether it possesses laws comparable to human (civil, religious, scientific) laws, and whether they are accessible to us as laws of physics (today's physics or a future physics). The answer could be yes if nature were, for example, our language, if nature were physics, but it is generally said that nature is the object of study of physics. Do laws of nature exist? Probably, many physicists think so, because Galileo used to think so. And Galileo, in turn, used to think so because he was highly influenced by Platonism which, already highly valued by medieval theology, was even rediscovered during Humanism: in one way or another, Platonism dominated its time. According to Plato, things have dignity in themselves and, though an object is only an empirical entity, a transitory and relative expression of nature, it is, nevertheless, a kind of imitation of some pure "idea", to which it tends and to which humans can have access. Accordingly, Galileo saw natural phenomena as manifestations of an ideal, uncorrupted world, a hyperuranium called mathematics, accessible to human beings: and when humans get physical knowledge of something, they get a knowledge identical to God's knowledge from a qualitative point of view. They know like God, the difference being only quantitative: God knows much more, but not better. From Galileo's Il Saggiatore: "Philosophy is written in this grand book, which stands continually open before our eyes (I say the 'Universe'), but can not be understood without first learning to comprehend the language and know the characters as it is written. It is written in mathematical language, and its characters are triangles, circles and other geometric figures, without which it is impossible to humanly understand a word; without these one is wandering in a dark labyrinth" [20]. So, Galileo was strongly religious and Platonic: his vision was fundamental for physics to be born and in order to understand the importance of using mathematics (and the importance of 'language'!), but was slightly put into crisis by the advent of non-Euclidean geometries, modern relativity and quantum theory. Ultimately, it is the vision of classical physics. Definitely, it is a philosophical vision.

But nature, well, probably doesn't care a thing of human laws. Even, of "ultimate laws": science, we scientists must know, is made up of approximations. Bertrand Russell once said "physics is mathematical not because we know so much about the physical world, but because we know so little: it is only its mathematical properties that we can discover" [21]. Indeed, I say, if we mathematically investigate the world, nothing but mathematical answers we'll get. Many physicists certainly had and still have a clear idea of the existence of these issues. Also Bohr, who in a somehow positivistic way formulated the Copenhagen interpretation and said "nothing exists until it is measured", was, on the other hand, perhaps well aware of the meaning of his words. Aage Petersen, in his memory [22] of the Danish physicist, states that, when asked about quantum world, Bohr answered "there is no quantum world. There is only an abstract quantum physical description. It is wrong to think that the task of physics is to find out how nature $i s$. Physics concerns what we can say about nature". Physics is the best 
tool to investigate nature in the sense of physical world, and how could it be otherwise? In my opinion, identifying science with reason, knowledge and nature is, other than a philosophical position, an act of faith. Which not only doesn't care about Socrates, Plato, Nietzsche, or Wittgenstein: after all, who cares. Which not only is mixing gnosiology and ontology, subject and object, signifier and signified, language and world, the word and the meaning: after all, these are philosophical and objectionable distinctions. Rather, it is mixing ornithology and birds: and, we know, birds don't care. 


\section{References}

[1] Stenger, Victor J., James A. Lindsay, and Peter Boghossian. "Physicists are philosophers, too." Scientific American 48 (2015).

[2] Rovelli, Carlo. "Physics needs philosophy. Philosophy needs physics." Foundations of Physics 48.5 (2018): 481-491.

[3] Aristotle. Protrepticus or Exhortation to Philosophy. 353-352 B.C. http://www.protrepticus.info/, retrieved June 2020

[4] Laplane, Lucie, et al. "Opinion: Why science needs philosophy." Proceedings of the National Academy of Sciences 116.10 (2019): 3948-3952.

[5] Weinberg, Steven. Dreams of a final theory. The Scientist's Search for the Ultimate Laws of Nature. Vintage, 1994.

[6] Rovelli, Carlo. "Aristotle's Physics: A Physicist's look." Journal of the American Philosophical Association 1.1 (2015): 23-40.

[7] Hawking, Stephen, Leonard Mlodinow. The grand design. Random House Digital, Inc., 2010.

[8] The Poetry of Science: Richard Dawkins and Neil deGrasse Tyson, https://www.youtube.com/watch?v=9RExQFZzHXQ, retrieved June 2020

[9] Has Physics Made Philosophy and Religion Obsolete?. 2012. https://www.theatlantic.com/technology/archive/2012/04/has-physics-madephilosophy-and-religion-obsolete/256203/, retrieved June 2020

[10] Feynman, Richard P. The Pleasure of Finding Things Out: The Best Short Works of Richard P. Feynman. Hachette UK. 2005

[11] https://www.lexico.com/en/definition/philosophy, retrieved June 2020

[12] https://www.merriam-webster.com/dictionary/philosophy, retrieved June 2020

[13] "Philosophy" on en.wikipedia.org, retrieved June 2020

[14] The Encyclopedia Americana. A library of universal knowledge. Encyclopedia Americana Corp., 1918-20, on https://babel.hathitrust.org/cgi/pt?id=wu.89094370749, retrieved June 2020

[15] Encyclopedia of Philosophy vol. 7, Macmillan, 2005

[16] Heidegger, Martin. The Question Concerning Technology. 1954, first english edition 1977.

[17] Wittgenstein, Ludwig. Tractatus logico-philosophicus. 1921 
[18] Nietzsche, Friedrich W. On truth and lies in a nonmoral sense. 1896. In "Philosophy and Truth. Selections from Nietzsche's Notebooks of the early 1870's". Humanity Books. 1993.

[19] University of Chicago. Annual Register. 1896.

[20] Galileo, Il Saggiatore. 1623.

[21] Russell, Bertrand. An outline of philosophy. Routledge, 2009.

[22] Petersen, Aage. The philosophy of Niels Bohr. The Bulletin of the Atomic Scientists Vol. 19, No. 7 (September 1963). 